\title{
Fraud, Whistleblowing System, and Behavioral Aspect in Public Sector
}

\author{
Halim Dedy Perdana ${ }^{1}$, Nafsiah Mohamed ${ }^{2}$, Corina Joseph ${ }^{3}$, Intiyas Utami ${ }^{4}$ \\ \{halimperdanadedy@gmail.com¹, drkancil@gmail.com², corinajospeh1971@gmail.com³, \\ intiyas@staff.uksw.edu $\left.{ }^{4}\right\}$ \\ Universiti Teknologi Mara, 40450 Shah Alam \\ Selangor, Malaysia ${ }^{1,2,3,}$ Satya Wacana Christian University, Jalan Diponegoro Nomor 52-60, 50711 \\ Salatiga, Central Java, Indonesia ${ }^{4}$
}

\begin{abstract}
Whistleblowing is a form of anti-fraud strategy that can be applied in various organizations, including in the public sector. The facts show that public sector fraud in Indonesia is still going on, although it has implemented the whistleblowing system in the government sector. Fraud triangle indicates that fraud caused by pressure, opportunity and rationalization. Of these three factors, pressure and rationalization are influenced by individual factors. This indicates that the individual factor becomes one of the causes of fraud. Individual factors can be traced to behavioral aspects. This research presents a variety of whistleblowing mechanisms in the context of behavioral aspects.
\end{abstract}

Keywords: fraud, whistleblowing systems, behavioral aspects

\section{Introduction}

Whistleblowing is a strategy that can assist an organization mitigate the risk of fraud. However, implementing a whistleblowing strategy is not easy. It requires consideration of several factors and behavioral aspect. This paper will consider factors and behavioral aspect in relation to the implementation of a whistleblowing.

Fraud is one of the biggest threats to the organization, both in the public and corporate sectors. Bribery case is a fraud in the form of misappropriation of assets. One bribery case occurred in Indonesia, namely the bribery case of the Supreme Audit Agency (BPK) in 2016. Fraud on the organization can be done by internal parties such as employees, and externally as investors and creditors. Association of Certified Fraud Examiners (2018) said whistleblowing can reduce or overcome the fraud detection. Fraud that happening in organizations more expressed by employees in comparison with the external auditors and analysts (Seifert, Sweeney, \& Joireman, 2010).

Literature relating to whistleblowing is happens in the organization, either in government or the private sector has begun to emerge since the 1980s (Keil, Tiwana, Sainsbury, and Sneha, 2010). The topics had already highlighted the psychological and social aspects of factors beyond the personal that encourage a person to be a whistleblower (Vandekerckhove \& Lewis, 2012).

Whistleblowing an individual or organization disclosure of fraud committed by members of the organization through both internal and external reporting channels, better use of anonymous reporting channels or non-anonymous. Xu and Ziegenfuss (2008); Brink, Lowe, and Victoravich (2013); Andon, Free, Jidin, Monroe, and Turner (2016); and Brink, Lowe, and Victoravich (2017) examine the whistleblowing intentions associated with a system of rewards (incentives). Xu and Ziegenfuss (2008) indicates that internal auditors tend to report an error when a monetary reward in cash or in exchange for a contract of employment is provided.

Gao and Brink (2017) explained that there were five effective determinant of whistleblowing that is characteristics of the whistleblower, the characteristics of the recipient of the report, the characteristics of the wrongdoers, the characteristics of wrongdoing and organizational characteristics. Three characteristics of whistleblower described by Miceli et al. (2008) are the characteristics of personality, moral considerations and demography. Personality characteristics of an internal factor that drives an individual's behavior. 
The decision process whistleblower influenced by three aspects: personal characteristics (Bartels, Bauman, Cushamn, Pizarro, and McGraw, 2014; Miceli et al., 2008). Brink, Cereola, \& Menk, (2015) investigated the personality traits with Big Five Factor of the reporting fraud and ethical position that is associated with whistleblowing intention.

This paper aims to review the various aspects of behavior that affect the whistleblowing intention. The paper consists consider fraud and its causes, the theory of planned of behavior, as well as the whistleblowing system and behavioral aspects. The final part of this paper is the conclusion as well as practical implications.

\section{Literature Review}

\subsection{Fraud and Causes}

ACFE (2016) declare fraud is a problem that will continue to thrive in today's world. That is, because the perpetrators of fraud can not only be the elite but also from the middle class and lower class employees. Rezaee (2005) describes the fraud as an intentional act by a made-up by an entity which may result in ownership of benefits that are not valid. Clinard and Cressey (1954) explain the three points of fraud factors usually presented in a triangular diagram. The points contained in the triangular diagram of the pressure, opportunity, and rationalization (Houck et al., 2006).

The perceived pressure refers to the factors that lead to unethical behavior. Every perpetrator of fraud faces some pressure to perform unethical behavior (Abdullahi and Mansor, 2015). Lister (2007) explains the pressure to commit fraud as the source of the beginning of the occurrence of a fraud. This pressure does not become a reason to commit fraud. Significant factors to commit fraud are understood through analysis of pressure that is personal, employment, stress, and external. Hooper and Pornelli (2010) said that stress can occur either through a positive or negative force.

Opportunity tajes advantage of an ineffective control or governance system that allows individuals to commit fraud within on an organization. In the field of accounting, this is referred to as an internal control weakness. Several factors give an employee the opportunity to commit fraud in an organization such as employee policy violations negligence and lack of disciplinary action (Sauser, 2007). Rae and Subramaniam (2008) said the chance that refers to the ability and the strength of an employee to realize his weakness and exploit organizational system with fraud. Hooper and Pornelli (2010) found that the chance of having two element, which are attached to the organization's vulnerabilities to manipulation and conditions in which the organization may require a fraud case.

Rationalization is difficult to note before or during a fraud, because it is difficult to read the mind of fraud perpetrators. Individuals who commit fraud have a certain mindset that allows the actors to justify or forgive the perpetrators of fraudulent actions (Hooper and Pornelli, 2010). Rationalization is the justification of fraudulent behavior due to a lack of personal integrity or moral reasoning (Rae and Subramaniam, 2008). The tendency to commit a fraud relies on ethical values and also on the personal attitude of the individual (Kenyon and Tillton, 2006). Howe and Malgwi (2006) found links between stress and opportunity when someone can rationalize the fraudulent behavior. Data on fraud committed in Indonesia is presented in Table 1.

Table 1. Data Fraud Most Adverse in Indonesia

\begin{tabular}{lcc}
\hline Fraud type & Number of Cases & Percentage \\
& & \\
\hline Corruption (Corruption) & 178 & $77 \%$ \\
Abuse Asset / Wealth & 41 & $19 \%$ \\
Organization (Asset & & \\
Missappropriation) & 10 & $4 \%$ \\
$\begin{array}{l}\text { Frauding Financial Report (Financic } \\
\text { Statement Fraud) }\end{array}$ & & \\
\hline
\end{tabular}

Source: Survey of Fraud Indonesia, ACFE 2016

\subsection{Theory of Planned Behavior (TPB)}

Factors that encourage whistleblowing can be explained by the theory of Planned Behavior (TPB) developed by Ajzen and Fishbein in 1988 and 1991. TPB explain the behavior of individuals that do arise 
because of the intention of the individual to behave and intentions of individuals caused by several internal and external factors of the individual.

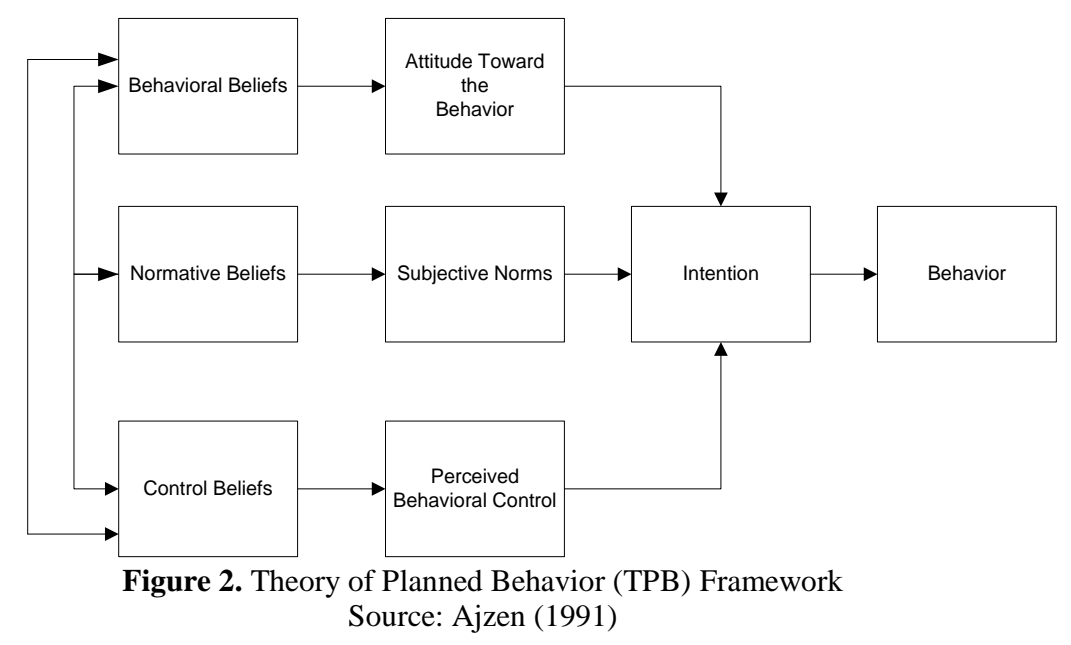

TPB explained that the intention of the individual to behave is determined by three factors: first, the attitude toward a behavior. Attitude is not a behavior, but the attitude of readiness to deliver an action that leads to behavior (Lopez, 2005). Individuals will do things according to its attitude toward a behavior. In addition, the individual will evaluate or assess whether the behavior is a good thing to do or not. Second, subjective norm which refers to the perception of the perceived social pressure to perform or not perform the behavior. Individuals will perform a behavior if it is considered acceptable behavior by people as important in his life. Third, the perception of behavioral control that refers to the ease or difficulty of doing the behavior. Control of an individual to behavior caused by internal factors and external factors. Internal factors come from within the individual such as willingness, skills, information, and others. External factors originating from outside the individual or of the environment around the individual. Perceptions of control behavior is how a person understands that he showed behavior is the result of controls carried out by himself.

TPB has been applied in several studies that tax compliance (Bobek and Hatfield, 2003), the behavior of public accountants (Buchan, 2005), the ethical decision manager (Carpenters and Reimers, 2005), the behavior of whistleblowing by the Chief Financial Officer (Uddin and Gillett, 2002), whistleblowing intentions on business students (Montesarchio, 2009), budgeting ( $\mathrm{Su}$ and Ni, 2013), in the auditor's whistleblowing intentions (Park and Blekinshopp, 2008).

An individual will have an intention to act in him before he did anything he wanted to do. When individuals have a perception and a positive attitude, have confidence that the behavior can be accepted by the surrounding environment, and believe that anything he does is the result of the controls themselves then the individual will have the intention to show a behavior. Someone will act as whistleblowers when perception, confidence and a positive attitude that what he will do in the process of whistleblowing is aimed at good and acceptable to the surrounding environment.

Park and Blenkinsopp (2009) stated that the TPB can be a general theory suitable for whistleblowing intention, because it shows the cause of whistleblowing three key factors, namely: attitudes, subjective norms, and perceived behavioral control. Alleyne et al. (2013) highlighted that a person's attitude is the assessment of the level of approval or rejection of a particular behavior. Subjective norms are social pressures that arise and may affect the perception of a particular behavior. Control behavior is a perception of the strength of the factors that can facilitate or complicate perform certain behaviors (Bird, Panter, Baker, Jones, \& Ogilvie, 2018).

Individuals also will weigh anonymous reporting channels as a means to protect his identity as a reporter, so the possibility of retalliation can be avoided. Therefore, in the perception of behavioral control, incentives and anonymous reporting line into factors that can simplify and complicate the 
individual to cause whistleblowing intentions. Cognition whistleblowing system with incentives and reporting channels anonymity, then people will feel motivated. Taylor, Bierstaker, and Brazel (2015) stated that monetary incentives are useful as a means of balancing risks. Lowe et al. (2015) mention the anonymous reporting channels useful for protecting whistleblowers from retaliation threats. From these statements mean that in the perception of behavioral control, the individual will weigh incentives as a form of appreciation for what he has done and is accompanied by risks associated therein. Individuals also will weigh anonymous reporting channels as a means to protect his identity as a reporter, so the possibility of retaliation can be avoided. Therefore, in the perception of behavioral control, incentives and anonymous reporting line into factors that can simplify and complicate the individual to cause whistleblowing intentions.

\subsection{Whistleblowing System and Behavioral Aspects}

Whistleblowing by employees in the local government can bring critical knowledge of the misconduct and the failure of the policy to be a priority by politicians (Skivenes and Trygstad 2016). Whistleblowing carries the risk when the information becomes publicly available to the public (Davis, 2003; Jubb, 1999; Weiss, 1994). However there refused to do whistleblowing as an internal mechanism for reporting fraud (Callahan \& Collins, 1992; Dandekar, 1991; Vandekerckhove \& commers, 2004). With reference to Miceli and Near (1985), whistleblowing occurs when employees choose the path to reveal internal rather than external fraud, including to the media.

There are two types of whistleblowing, namely (a) internal whistleblowing, occurs when one or several employees aware of fraud by employees or management, then report the fraud to the company leader; and (b) external whistleblowing, occurs when a person fraud committed employees know the company and then leaked to the public because he knew that such fraud would be detrimental to the public.

Whistleblowing is the disclosure by members of the organization of the practice illegal, immoral or illegitimate practices under the control of the employee to the organization that affect the actions (Near \& Miceli, 1985, 4; Near et al., 2004; Miceli et al., 2008, 8). Whistleblowing is important for a variety of reasons, namely to safeguard or improve the welfare of employees with emphasis on democracy as a right in upholding ethics in the organization. Employees may do whistleblowing when disagreeing with his boss (Glazer and Glazer, 1999; Miceli, Near, \& Dworkin, 2008). The research also states that the whistleblower bold as to ignore the risks or play the "blame game" to establish responsibility of a risk (Kesselheim, Studdert, and Mello, 2010).

Blowing the whistle may affect interpersonal relations between whistleblowers, co-worker and the accused. The whistleblower may be derived from a loyal worker for being disloyal. This means that they do not recognize the authority of management (Davis, 2003). Glazer and Glazer (1989) stated that whistleblowers should try to rebuild their lives by finding another job and develop a new career.

Kaplan, Pany, Samuels, and Zhang (2012) investigate fraud reporting channel preference witness to experiment and discover the intention of reporting witness through an anonymous channel is higher than non-anonymous channel only when the previous whistleblowing negative results (no retaliation against whistleblowers).

Whistleblowing conditions also influenced by the model of individual ethical orientation (Forsyth 1992). Brink, Cerelola et al. (2015) predicted and found that individuals with idealistic ethical position is more likely to whistleblowing than individuals with ethical relativist position. Brink, Lowe and Victoravich (2017) tested the whistleblower stance on monetary (Yamauchi and Templer 1992) is influenced by external and internal whistleblowing channels.

Other individual factors, namely the demographic characteristics are also influenced by the characteristic aspects of the whistleblower. Experimental research on demographic information on participants such as age, gender, and type of employees do not relate to the desire of reporting (eg, Brink, Lowe, \& Victoravich, 2013; Kaplan, Pope, \& Samuels, 2011; Seifert, Sweeney, Joireman, \& Thornton, 2010).

Some research on the influence of individual characteristics, strength of the evidence and incentives on whistleblowing has been studied by Brink et al. (2013) with the experiment at 81 MBA students. The research results Brink et al. (2013) showed that internal reporting is greater than reporting to the SEC, and the stronger the evidence that internal rewards to improve reporting to the SEC. Research 
of Brink, Cereola et al. (2015) examined the materiality wrongdoing, personality traits and ethical position with the experiment and the results show the materiality of wrongdoing affecting the whistleblower. Brink, Eller et al. (2015) provides empirical evidence that the whistleblowing intention related to the strength of the evidence and concern for the actions of employees.

In relation to personality characteristics and moral judgment, Curtis and Taylor (2009) provide empirical evidence that whistleblowing in public accounting firms caused by the perspective of locus of control and ethical style. Locus of control refers to how the attributes of internal factors (eg, hard worker) or external factors (luck). Ethical style describes an individual approach to ethical dilemmas. Dalton and Radtke (2013) tested the effects of Machiavellianism join and ethical environment against whistleblowing. The nature of Machiavellianism is the tendency of individuals to deceive others in order to achieve his personal goal (Christie and Geis, 1970). Dalton and Radtke (2013) found that negative influence between Machiavellianism and whistleblowing. Brink, Cereola and Menk (2015) investigated the characteristics of the individual personality that Big Five Personality and ethical position with whistleblowing intention. Based on these, whistleblowing intention is influenced by factors of individual behavior.

\section{Conclusion}

This paper presents the public sector fraud and whistleblowing system influenced by behavioral aspects. Behavioral factors that encourage whistleblowing system among other personality factor, Machiavellianism, Locus of Control and demographic factors (age, gender). Whistleblowing personality factors are supported by an effective system, namely the anonymous reporting channels.

\section{References}

[1]Andon, P., Free, C., Jidin, R., Monroe, G. S., \& Turner, M. J.: The impact of financial incentives and perceptions of seriousness on whistleblowing intention. Vol. 151, pp 165-178. Journal of Business Ethics (2016)

[2]Bird, E. L., Panter, J., Baker, G., Jones, T., \& Ogilvie, D.: Predicting walking and cycling behaviour change using an extended theory of planned behaviour. Journal of Transport and Health. (2018)

[3]Brink, A. G., Lowe, D. J., \& Victoravich, L. M.: The effect of evidence strength and internal rewards on intentions to report fraud in the Dodd Frank Regulatory Environment. Vol. 32, pp 87-104. Auditing: A Journal of Practice \& Theory (2013)

[4]Brink, A. G., Lowe, D. J., \& Victoravich, L. M.: The public company whistleblowing environment: Perceptions of a wrongful act and monetary attitude. Accounting and the Public Interest (2017)

[5]Callahan, E. S. \& Collins, J. W.: Worker attitudes towards whistleblowing: Management and public policy implications. Vol. 11, pp 939-948. Journal of Business Ethics (1992)

[6]Christie, R., \& Geis, F. L.: How devious are you? Take the Machiavelli test to find out. Journal of Management in Engineering (1970)

[7]Curtis, M. B., \& Taylor, E. Z.: Whistleblowing in public accounting: Influence of identity disclosure, situational context, and personal characteristics. Vol. 9, pp 191-220. Accounting and the Public Interest (2009)

[8]Dalton, D., \& Radtke, R. R.: The joint effects of Machiavellianism and ethical environment on whistle-blowing. Vol 117, pp 153-172. Journal of Business Ethics (2013)

[9]Davis, M.: Whistleblowing. The Oxford handbook of practical ethics. pp. 539-565. Oxford: Oxford University Press. (2003)

[10]Glazer, M. P. \& Glazer, P. M.: The whistleblowers: Exposing corruption in government and industry. New York, NY: Basic Books (1989)

[11]Jubb, P. B.: Whistleblowing: A restrictive definition and interpretation. Vol. 21, pp 77-94. Journal of Business Ethics (1999)

[12]Kaplan, S. E., Pope, K. R., \& Samuels, J. A.: The effect of social confrontation on individuals' intentions to internally report fraud. Vol. 22, pp 51-67. Behavioral Research in Accounting (2010)

[13]Kaplan, S. E., Pany, K., Samuels, J., \& Zhang, J.: An examination of anonymous and non-anonymous fraud reporting channels. Vol. 28, pp 88-95. Advances in Accounting (2012)

[14]Kesselheim, A. S., Studdert, D. M., \& Mello, M. M.: Whistle-blowers' experiences in fraud litigation against pharmaceutical companies. Vol. 362, pp 1832-1839. New England Journal of Medicine (2010)

[15]Miceli, M. P. \& Near, J. P.: Characteristics of organizational climate and perceived wrongdoing associated with whistle-blowing decisions. Vol. 38, pp 525- 544. Personnel Psychology (1985)

[16]Miceli, M., Near, J. \& Dworkin, T.: Whistleblowing in organizations. New York, NY: Routledge. (2008)

[17]Near, J. \& Miceli, M.: Does type of wrongdoing affect the whistle-blowing process? Vol. 14, pp 219-242. Business Ethics Quarterly (2004) 
[18]Near, J. P., Rehg,M., Miceli, M. P. \& Van Scotter, J. R.: Developing a model of the whistle-blowing process: How does type of wrongdoing affect the process? Vol. 14, pp 219-242. Business Ethics Quarterly (2004)

[19]Park, H., \& Blenkinsopp, J.: Whistleblowing as planned behavior - a survey of south Korean Police Officers. Vol. 85, pp 545-556. Journal of Business Ethics, (2009)

[20]Seifert, D. L., Sweeney, J. T., Joireman, J., \& Thornton, J. M.: The influence of organizational justice on accountant whistleblowing, Vol. 35, pp 707-717. Accounting, Organizations and Society (2010)

[21]Vandekerckhove, W., \& Commers, M. S. R.: Whistle blowing and rational loyalty. Vol. 53, pp 225-233. Journal of Business Ethics (2004)

[22]Xu, Y., \& Ziegenfuss, D. E.: Reward systems, moral reasoning, and internal auditors' reporting wrongdoing. Vol. 22, pp 323-331. Journal of Business and Psychology (2008)

[23]Weiss, J. W.: Business ethics: A managerial, stakeholder approach. Belmont, Calif: Wadsworth (1994) 